How Many Species are There on Earth?

\author{
Robert M. May
}

Science, New Series, Vol. 241, No. 4872. (Sep. 16, 1988), pp. 1441-1449.

Stable URL:

http://links.jstor.org/sici?sici=0036-8075\%2819880916\%293\%3A241\%3A4872\%3C1441\%3AHMSATO\%3E2.0.CO\%3B2-B

Science is currently published by American Association for the Advancement of Science.

Your use of the JSTOR archive indicates your acceptance of JSTOR's Terms and Conditions of Use, available at

http://www.jstor.org/about/terms.html. JSTOR's Terms and Conditions of Use provides, in part, that unless you have obtained prior permission, you may not download an entire issue of a journal or multiple copies of articles, and you may use content in the JSTOR archive only for your personal, non-commercial use.

Please contact the publisher regarding any further use of this work. Publisher contact information may be obtained at http://www.jstor.org/journals/aaas.html.

Each copy of any part of a JSTOR transmission must contain the same copyright notice that appears on the screen or printed page of such transmission.

JSTOR is an independent not-for-profit organization dedicated to and preserving a digital archive of scholarly journals. For more information regarding JSTOR, please contact support@jstor.org. 


\title{
Articles
}

\section{How Many Species Are There on Earth?}

\author{
Robert M. MAY
}

This article surveys current answers to the factual question posed in the title and reviews the kinds of information that are needed to make these answers more precise. Various factors affecting diversity are also reviewed. These include the structure of food webs, the relative abundance of species, the number of species and of individuals in different categories of body size, along with other determinants of the commonness and rarity of organisms.

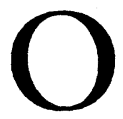

VER A CENTURY AGO, DARWIN AND OTHERS PROVIDED the broad outline of an answer to the question of how life has evolved on Earth and how species originate. The next question would seem to be how we use this basic understanding to estimate-from first principles-how many species are likely to be found in a given region or, indeed, on Earth as a whole.

Surprisingly, this question of "how many species?" has received relatively little systematic attention, from Darwin's time to our own. At the purely factual level, we do not know to within an order of magnitude how many species of plants and animals we share the globe with: fewer than 2 million are currently classified, and estimates of the total number range from under 5 million to more than 50 million. At the theoretical level, things are even worse: we cannot explain from first principles why the global total is of the general order of $10^{7}$ rather than $10^{4}$ or $10^{10}$.

This article first surveys various kinds of empirical and theoretical studies that are helping to give us a better idea of how many species, or how many individual organisms, we might expect to find in a given environment. Such studies include the structure of food webs, patterns in the relative abundance of species, patterns in the number of species or number of individuals in different categories of physical size, and general observations about trends in the commonness or rarity of organisms. The article then reviews current evidence about the total number of species on Earth, indicating lines of research that could sharpen the estimates. We do not end up with a list of answers, but rather with a list of more sharply focused questions.

\section{The Structure of Food Webs}

Cohen and Briand $(1,2)$ have compiled and analyzed a catalog that now includes 113 food webs, embracing a wide variety of natural environments ( 55 food webs from continental settings- 23 terrestrial and 32 aquatic-along with 45 coastal and 13 oceanic webs). The data for these food webs are of uneven quality, with the

This article was written while the author was in the Department of Biology, Princeton University, Princeton, NJ 08544. His present address is Department of Zoology, Oxford University, Oxford, OXI 3PS, England. most notable problem being that some studies identify individual species ("blue jays") whereas others deal with aggregates ("spiders," "copepods," or even "zooplankton"); some studies articulate individual species of predators at upper levels but aggregate coarsely at lower trophic levels (3). Even so, some remarkable regularities emerge from Cohen and Briand's analysis of these data $(1,2)$.

For one thing, the average number of other species with which any one species interacts directly is consistently around 3 to 5 (4). The number is consistently higher (average, 4.6) in relatively constant environments than in fluctuating ones (average, 3.2). There are also consistent and quantitative patterns in the proportions of basal, intermediate, and top predator species (those whose links reach only upward, both ways, and only downward, respectively); the ratios are $0.19: 0.53: 0.29$, respectively (5). A similar pattern of "link-scaling" invariance is found for the ratio of links among the four categories of basal-intermediate, basal-top, intermediate-intermediate, and intermediate-top $(0.27: 0.08: 0.30: 0.35$, respectively). Most interestingly, these two quantitative patterns in the proportions of species in different trophic categories, and in "link-scaling," can be deduced from the empirical observation that each species is directly connected to roughly four others, along with

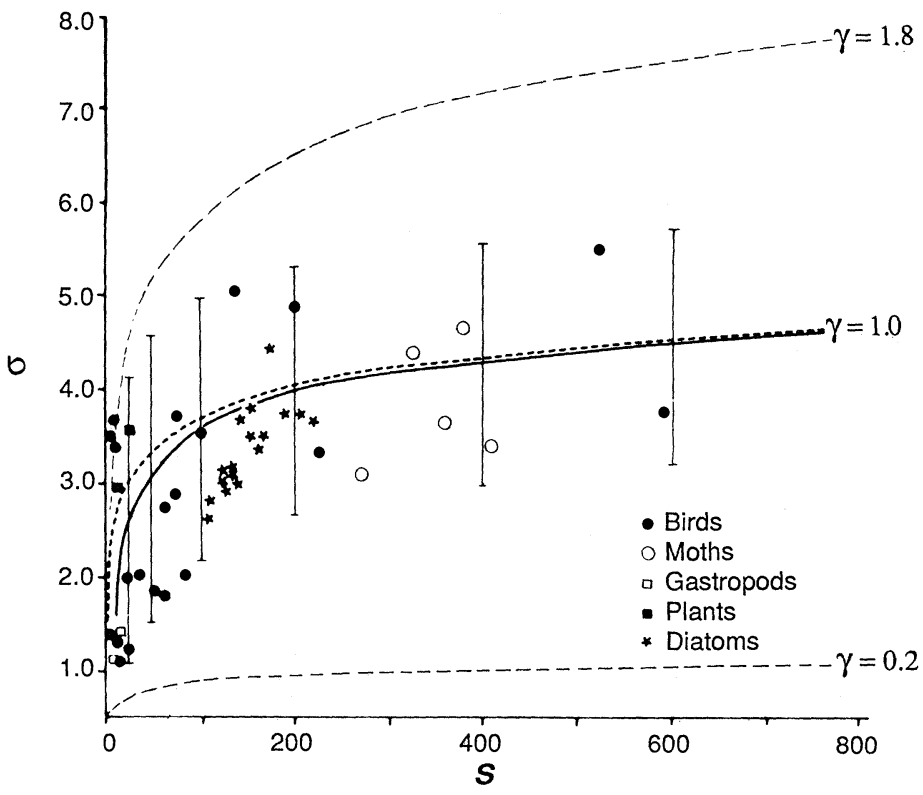

Fig. 1. A plot of $S$, the number of species, versus $\sigma$, the standard deviation of the logarithms of the relative abundances, for various communities of birds, moths, gastropods, plants, and diatoms. The dashed line labeled $\gamma=1.0$ shows the relation between $S$ and $\sigma$ for Preston's (15) "canonical" lognormal distribution; the lines labeled $\gamma=0.2$ and $\gamma=1.8$ are the bounds to the range of $S-\sigma$ relations that might be expected from general mathematical properties of the lognormal distribution, for large $S$ and reasonable ranges of values for the total number of individuals, $N$. The solid line is the mean relation predicted by Sugihara's (17) model, and the error bars represent \pm 2 standard deviations about this mean. 
Table 1. The distribution of 160 plant species from the Biological Flora of the British Isles, classified into eight categories according to geographic distribution (wide or narrow), habitat specificity (broad or restricted), and local abundance (somewhere large or everywhere small) (34).

\begin{tabular}{lccccc}
\hline \multirow{2}{*}{$\begin{array}{c}\text { Local } \\
\text { population } \\
\text { size }\end{array}$} & \multicolumn{3}{c}{ Geographic distribution } \\
\cline { 2 - 3 } & \multicolumn{2}{c}{$\begin{array}{c}\text { Wide } \\
\text { habitat specificity }\end{array}$} & & \multicolumn{2}{c}{$\begin{array}{c}\text { Narrow } \\
\text { habitat specificity }\end{array}$} \\
\cline { 2 - 3 } \cline { 5 - 6 } & Broad & Restricted & & Broad & Restricted \\
\hline $\begin{array}{l}\text { Somewhere large } \\
\text { Everywhere small }\end{array}$ & 58 & 71 & & 6 & 14 \\
\hline
\end{tabular}

the assumption that the species are ordered in a cascade or hierarchy, such that a given species can prey on only those below it and can be preyed on only by those species above it in the hierarchy [an assumption that several authors $(2,6)$ have independently suggested may follow from body-size considerations between predators and their prey].

Other patterns in the ratios between numbers of interacting species in different trophic levels are the subject of continuing investigation. Hawkins and Lawton (7) have observed that food chains comprising green plants, insect herbivores, and insect parasitoids include over half of all known species of metazoans, so that understanding what determines the richness of parasitoid species could be a major step toward understanding the diversity of terrestrial communities. They analyzed data for 285 species of herbivorous insects, from 42 families, in Britain, and found the typical such species to be attacked by 5 to 10 species of parasitoids; the number depends significantly on the geographical range of the host insect, on the architecture of the host plant, and to a lesser extent on a variety of other factors (7). Preliminary data suggest that the tropics are roughly similar to Britain, in that herbivorous insects are hosts to around five to ten species of parasitoids (8). Other studies document systematic patterns in the number of phytophagous insect species associated with different plant hosts (9) and in the ratios between numbers of species of prey and predators of various kinds $(10)$.

It could be that many of these apparent patterns tell us more about the workings of the human mind, and about how we tend to collect and categorize data, than they do about the natural world (11). Moreover, the populations in real food webs can have extremely complex dynamical behavior, with nonlinearities in densitydependent factors producing cyclic or chaotic changes in abundance and with unpredictable environmental fluctuations adding further complications; it seems unlikely that the salient features of such dynamical systems can be captured in static analyses of food web graphs (12). These caveats and complications notwithstanding, the patterns discussed above are intriguing. If they stand up to further study, they could simplify the task of understanding diversity. It could be, for example, that one need only understand what determines the number of plant species, and then the total faunal diversity could be deduced from appropriate rules.

\section{Relative Abundance of Species}

Real understanding of food webs in particular, and of diversity in general, must go beyond the mere presence or absence of species to an understanding of relative abundance. In early successional communities, and in environments disturbed by toxins or "enriched" by pollution, steeply graded distributions of species relative abundance (SRA) are commonly seen, with a handful of dominant species accounting for most of the individuals present. Conversely, in relatively undisturbed "climax" communities consisting of many species, relatively even distributions of relative abundance are typical; very often, such SRAs are distributed according to a "canonical lognormal" distribution, as illustrated in Fig. 1. Such trends in SRAs show up in studies of old field succession (13). The effects of pollution or other systematic disturbances reveal the same trend, except that time effectively runs backward, so that the progression is from evenness to dominance (14).

It is not surprising that the relative abundances within a fairly large and relatively undisturbed group of species will be disturbed lognormally. The relative abundances are likely to be governed by the interplay of many more or less independent factors. It is in the nature of the equations of population dynamics that these several factors should compound multiplicatively, and the statistical central limit theorem applied to such a product of factors implies a lognormal distribution. This general observation, however, tells us nothing about the relation between $\sigma$ (the standard deviation of the logarithms of the relative abundances) and $S$ (the total number of species present). The puzzling fact is that very many assemblies have SRAs that obey the canonical lognormal distribution, that is, that have the unique relation between $\sigma$ and $S$ illustrated by the curve labeled $\gamma=1.0$ in Fig. 1, although this curve represents just one of an infinite family of possible lognormal distributions (15).

It has been conjectured that the canonical property may be merely an approximate mathematical property of all lognormal distributions for large $S$; the dashed curves in Fig. 1 labeled $\gamma=1.8$ and $\gamma=0.2$ represent plausible boundaries to the $\sigma-S$ relation on this basis (16). The data put together by Sugihara (17) in Fig. 1 make it clear, however, that real SRAs obey the canonical relation more closely than can be explained by these mathematical generalities alone. Sugihara has also suggested a biological mechanism that will produce the observed patterns. He imagines the multidimensional "niche space" of the community as being a hypervolume broken up sequentially by the component species (with any fragment being equally likely to be chosen for the next breakage, regardless of size), such that each of the $S$ fragments denotes the relative abundance of a species. Although the biological status of this assumption is debatable, it generates patterns of SRA in accord with a large number of data (the solid line in Fig. 1 shows the mean relation between $S$ and

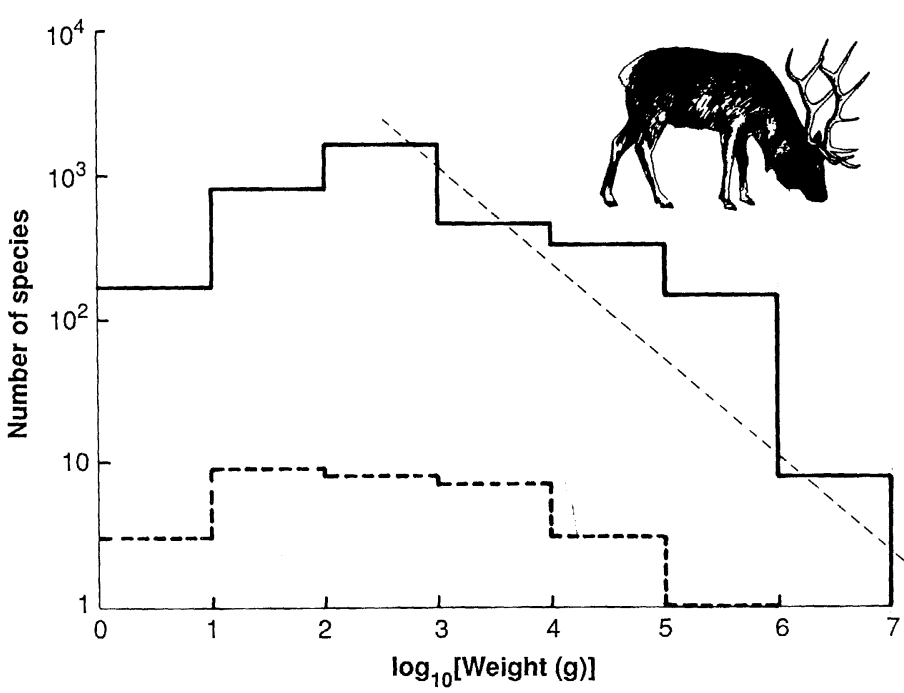

Fig. 2. The numbers of species, $S$, of all terrestrial mammals (solid histogram) and of British mammals (dashed histogram), excluding bats, are shown distributed according to mass categories (mass expressed in grams) $(18,19)$. Note the doubly logarithmic scale. The thin dashed line illustrates the shape of the relation $S \sim L^{-2}$, where $L$ is the characteristic length $(20)$. 
$\sigma$ predicted by the model, and the error bars show the range of \pm 2 standard deviations about the mean). Such a fit does not, of course, validate the model; it is possible that other biological assumptions could produce similar distributions of SRA.

One problem with essentially all the data that have been compiled for SRA is that they focus on particular taxonomic groups ("birds," "moths"). To understand how communities are assembled, it may be more relevant to inquire about the relative abundance within ecologically similar groups (putting birds together with bats and some large insects, for instance).

\section{Number of Species Versus Physical Size}

A variety of other patterns in the distribution and abundance of organisms have received little attention. For example, how many species do we expect to find in different categories of physical size, within a given region?

The meager amount of available information bearing on this question is reviewed elsewhere (18). Figure 2 gives one representative study, showing the way in which all $\mathbf{3 0 0 0}$ or so mammalian species, excluding bats and marine mammals, are apportioned among mass classes (19). A corresponding analysis, but restricted to the mammal species of Britain, again excluding bats and marine mammals, is also shown in Fig. 2 (18). Although Britain's mammals appear to obey the global pattern of species versus size, appropriately scaled down, this may not be true in general; there is no a priori reason to expect the species-size patterns for faunal assemblies from relatively small areas to be the same as those from large (and correspondingly more environmentally diverse) areas.

Figure 2 and similar analyses represent rough assessments of the facts. Very few ideas have been advanced in explanation of these facts about species-size distributions. Hutchinson and MacArthur (20) have advanced arguments for expecting an $L^{-2}$ relation between the number of species and the characteristic length of constituent individuals, $L$. The argument is essentially that, for terrestrial organisms, the world is seen as two-dimensional, and therefore the possibility of finding new roles (and thence new species) may scale as $L^{-2}$. This conjectured $L^{-2}$, or $M^{-2 / 3}$, relation, where $M$ is mass, is illustrated by the dashed straight line in Fig. 2.

\section{Number of Individuals Versus Physical Size}

Other patterns can be sought in the relation between numbers of individuals and their physical size (mass or characteristic length). For example, in a particular region, how is the number of individual animals in the size class from 0.1 to $1 \mathrm{~cm}$ related to the number in the class from 1 to $10 \mathrm{~cm}(21,22)$ ?

In particular, Morse et al. (21) and Brown and Maurer (23) have collated data about populations of phytophagous insects and of birds, respectively, and have advanced qualitative explanations for these data. Morse et al. began with the assumption that roughly equal amounts of energy flow through each size category; although very unlikely to be true in general, this assumption is supported by some evidence from organisms ranging widely in size (24). Given this assumption, along with the usual manner in which metabolic costs become relatively larger at smaller sizes, the total number of individuals, $N$, in the size class with characteristic mass $M$ and length $L$ may be expected to scale as $N \sim M^{-0.75} \sim L^{-2.25}(25)$. That is, for a 10-fold decrease in characteristic length we would, on this basis, expect a roughly 180 -fold increase in the total number of individuals.

Recent insights into the fractal geometry of nature suggest, however, that the structure of the habitat-and hence the number of possible ways of making a living-is unlikely to scale linearly with $L$ (26). Consider, for example, the circumference of a large tree, or any other "one-dimensional" object. If we measure it on a $10-\mathrm{cm}$ scale, we get one answer. On a $1-\mathrm{cm}$ scale, we will often get another, larger answer. A yet larger answer would be obtained on a $1-\mathrm{mm}$ scale, and so on. The circumference of the tree is thus not simply one dimensional but has a "fractal dimension," $D$, such that the perceived length, $\ell(\lambda)$, depends on the step-length of measurement, $\lambda$, as $\lambda^{1-D}: \ell(\lambda)=c \lambda^{1-D}$, where $c$ is a constant. If $D=1.5$, for example, a 10-fold reduction in the measurement scale (from, say 10 $\mathrm{cm}$ to $1 \mathrm{~cm}$ ) will result in the apparent length increasing by a factor $10^{0.5} \simeq 3$. Morse et al. applied these notions to measure the profiles of various kinds of vegetation at different scales, concluding that $D$ for such habitats ranged from around 1.3 to around 1.8, with an average around 1.5 (Fig. 3). That is, for herbivorous insects that exploit their surroundings in an essentially one-dimensional way (using the edges of leaves, or the like) a 10 -fold decrease in physical size produces a roughly 3 -fold increase in the apparently available

Table 2. The number of species (to within an order of magnitude) in the different animal phyla, classified according to the habitat of adult animals. Most phyla are predominantly marine and benthic, some exclusively so. The numbers 1 through 5 indicate the approximate number of recorded living species: 1 means 1 to $10^{2} ; 2$ means $10^{2}$ to $10^{3} ; 3$ means $10^{3}$ to $10^{4} ; 4$ means $10^{4}$ to $10^{5}$; and 5 means $10^{5}$ or more. After (38). Abbreviations: B, benthic; $P$, pelagic; $M$, moist; $X$, xeric; Ec, ecto; and En, endo.

\begin{tabular}{|c|c|c|c|c|c|c|c|c|}
\hline \multirow{3}{*}{$\begin{array}{l}\text { Phylum } \\
\text { Subphylum }\end{array}$} & \multicolumn{8}{|c|}{ Habitat } \\
\hline & \multicolumn{2}{|c|}{ Marine } & \multicolumn{2}{|c|}{ Freshwater } & \multicolumn{2}{|c|}{ Terrestrial } & \multicolumn{2}{|c|}{ Symbioti } \\
\hline & B & $\mathbf{P}$ & B & $P$ & M & $\mathrm{X}$ & Ec & En \\
\hline Porifera & 3 & & 1 & & & & 1 & \\
\hline Placozoa & 1 & & & & & & & \\
\hline & & & & & & & & 1 \\
\hline Dicyemida & & & & & & & & 1 \\
\hline Cnidaria & 3 & 2 & 1 & 1 & & & 1 & \\
\hline Ctenophora & 1 & 1 & & & & & & \\
\hline Platyhelminthes & 3 & 1 & 3 & & 2 & & 1 & 4 \\
\hline Gnathostomulida & 2 & & & & & & & \\
\hline Nemertea & 2 & 1 & 1 & & 1 & & 1 & \\
\hline Nematoda & 3 & 1 & 3 & 1 & 3 & 1 & 3 & 3 \\
\hline \multirow{2}{*}{\multicolumn{9}{|c|}{$\begin{array}{l}\text { Nematomorpha } \\
\text { Acanthocephala }\end{array}$}} \\
\hline & & & & & & & & \\
\hline Rotifera & 1 & 1 & 2 & 2 & 1 & & 1 & 1 \\
\hline Gastrotricha & 2 & & 2 & & & & & \\
\hline Kinorhyncha & 2 & & & & & & & \\
\hline Loricifera & 1 & & & & & & & \\
\hline Tardigrada & 1 & & 2 & & 1 & & & \\
\hline Priapula & 1 & & & & & & & \\
\hline Mollusca & 5 & 1 & 3 & & 3 & 1 & 1 & 1 \\
\hline Kamptozoa & 1 & & 1 & & & & 1 & \\
\hline Pogonophora & 2 & & & & & & & \\
\hline Sipuncula & 2 & & & & 1 & & & \\
\hline Echiura & 2 & & & & & & & \\
\hline Annelida & 4 & 1 & 2 & & 3 & & 2 & \\
\hline & & & & & 1 & & & \\
\hline \multicolumn{9}{|l|}{ Arthropoda } \\
\hline Crustacea & 4 & 3 & 3 & 2 & 2 & & 2 & 2 \\
\hline Chelicerata & 2 & 1 & 2 & 2 & 4 & 3 & 2 & 1 \\
\hline Uniramia & 1 & 1 & 3 & 2 & 5 & 3 & 2 & 2 \\
\hline Chaetognatha & 1 & 1 & & & & & & \\
\hline Phoronida & 1 & & & & & & & \\
\hline Brachiopoda & 2 & & & & & & & \\
\hline Bryozoa & 3 & & 1 & & & & & \\
\hline Echinodermata & 3 & 1 & & & & & & \\
\hline Hemichordata & 1 & & & & & & & \\
\hline \multicolumn{9}{|l|}{ Chordata } \\
\hline Urochordata & 3 & 1 & & & & & & \\
\hline Cephalochordata & 1 & & & & & & & \\
\hline Vertebrata & 3 & 3 & 2 & 3 & 3 & 3 & 1 & 1 \\
\hline
\end{tabular}


habitat; for creatures that exploit their environment in an essentially two-dimensional way (using surfaces rather than edges), the effect must be squared, so that a 10 -fold decrease in physical size produces an effectively 10 -fold increase in apparent habitat. These two factors (the one-dimensional factor 3 and the two-dimensional factor 10) are likely to bound the range of possibilities found in actual assemblies of insects.

Combining these fractal aspects of habitat perception with the metabolic considerations discussed above, Morse et al. concluded that a 10-fold decrease in characteristic length, $L$, is likely to produce an increase in $N$ that lies between 500 and 2000 (that is, roughly between 3 and 10 times 180). As shown in Fig. 4, this very rough expectation is borne out surprisingly well by data for the number of individual arthropods of different body lengths found on vegetation in places ranging from primary forests, primary riparian vegetation, and secondary vegetation in the New World Tropics to temperate habits, for example, birch trees on Skipwith Common in Yorkshire.

The study by Morse et al. is a frankly speculative one. I have chosen to highlight it because it provides an explicit example where our thinking about aspects of population abundance and diversity needs to acknowledge that nature is often not Euclidean but rather may have fractal geometry, with organisms existing in spatial and temporal frameworks that are, as it were, jagged on every scale (27). This is an example where new mathematical concepts interact with biological ideas in potentially surprising ways (the chaotic behavior of many simple population models is another example).

\section{Species Numbers, Species Abundance, and Body Length}

Still other studies have focused on empirical relations between the abundance of individual species and the body size of constituent individuals $(25,28)$. I think any eventual understanding of the total number of species in a given environment, and thence ultimately of the diversity of life on Earth, will need to be based on a clear understanding of the interplay among all the factors discussed above. Yet most of the few existing studies have singled out one or other aspect (species size, species abundance) from the interwoven mosaic.

Exceptions are the work on birds by Brown and Maurer (23) and the recent study by Morse et al. of the relations among species number, species abundance, and body length for 859 species of arboreal beetles in lowland rain-forest trees in Borneo (29). Figure $5 \mathrm{~A}$ summarizes the results, showing the total number of species in different categories of population abundance and physical size (both plotted logarithmically); Fig. 5, B through E, correspondingly shows the number of species in different trophic categories. Although Fig. 5 does have some interesting structural details [for discussion, see (29)], it is essentially simple. It is encouraging that Fig. 5 has the basic features one would have guessed from the separate studies of species abundance, species size, and abundance size in different groups, as discussed above.

\section{Commonness and Rarity}

In the discussion above, some of the species found in a given region are confined to that region, whereas others (which are part of the species-size and other distributions in the region) are distributed much more widely. Partly for this reason, and partly for its intrinsic interest, it would be nice to know more about the distribution of geographical ranges within different taxonomic groups of species. What fraction of all bird species, for example, range globally over
$10 \%$ of the globe, over $1 \%$, and so on? Hanski (30), Brown (31), Root (32), Rapoport (33), and others have made a start toward answering this question, for diverse collections of organisms including vascular plants, intertidal invertebrates, terrestrial arthropods, planktonic crustaceans, and terrestrial vertebrates (especially birds), but much remains to be learned.

Intuitive ideas about commonness and rarity usually make reference both to geographical distribution and to local abundance. Such considerations often swirl together in ways that make it difficult to define exactly what constitutes a rare species. One type of rareness is, for example, exhibited by the silver sword, Argyroxyphium macrocephalum, that grows only in the crater of the Haleakala volcano on Maui. Although there are around 50,000 individuals in the large,

Table 3. A rough indication of the relative effort devoted to animals from different taxonomic groups is given by the average number of papers listed in the Zoological Record, 1978 through 1987 (54).

\begin{tabular}{|c|c|c|c|}
\hline $\begin{array}{l}\text { Phylum } \\
\text { Subphylum } \\
\text { Class } \\
\text { Order }\end{array}$ & $\begin{array}{l}\text { Average } \\
\text { number of } \\
\text { publications } \\
\text { per year } \\
\text { (coefficient } \\
\text { of variation, } \\
\text { in percent) }\end{array}$ & $\begin{array}{l}\text { Approximate } \\
\text { number of } \\
\text { recorded } \\
\text { species }\end{array}$ & $\begin{array}{l}\text { Papers } \\
\text { per } \\
\text { species } \\
\text { per } \\
\text { year }\end{array}$ \\
\hline Protozoa & $3,900(10)$ & 260,000 & 0.15 \\
\hline Porifera & $190(22)$ & 10,000 & 0.02 \\
\hline Coelenterata & $740(12)$ & 10,000 & 0.07 \\
\hline Echinoderma & $710(15)$ & 6,000 & 0.12 \\
\hline Nematoda & $1,900(1)$ & $1,000,000$ & 0.002 \\
\hline Annelida & $840(9)$ & 15,000 & 0.06 \\
\hline Brachiopoda & $220(14)$ & 350 & 0.63 \\
\hline Bryozoa & $160(15)$ & 4,000 & 0.04 \\
\hline Entoproctra & $7(53)$ & 150 & 0.04 \\
\hline Mollusca & $1,000(8)$ & 100,000 & 0.04 \\
\hline \multicolumn{4}{|l|}{ Arthropoda } \\
\hline Crustacea & $3,300(9)$ & 39,000 & 0.09 \\
\hline \multicolumn{4}{|l|}{ Chelicerata } \\
\hline Arachnida & $2,000(6)$ & 63,000 & 0.03 \\
\hline \multicolumn{4}{|l|}{ Uniramia } \\
\hline Insecta & $17,000(7)$ & $1,000,000(?)$ & 0.02 \\
\hline Coleoptera & $2,900(6)$ & 300,000 & 0.01 \\
\hline Diptera & $3,200(7)$ & 85,000 & 0.04 \\
\hline Lepidoptera & $3,500(9)$ & 110,000 & 0.03 \\
\hline Hymenoptera & $2,200(9)$ & 110,000 & 0.02 \\
\hline Hemiptera & $1,700(7)$ & 40,000 & 0.04 \\
\hline \multicolumn{4}{|l|}{ Chordata } \\
\hline \multicolumn{4}{|l|}{ Vertebrata } \\
\hline Pisces & $7,000(13)$ & 19,000 & 0.37 \\
\hline Amphibia & $1,300(12)$ & 2,800 & 0.47 \\
\hline Reptilia & $2,400(7)$ & 6,000 & 0.41 \\
\hline Aves & $9,000(10)$ & 9,000 & 1.00 \\
\hline Mammalia & $8,100(12)$ & 4,500 & 1.80 \\
\hline \multicolumn{4}{|c|}{ Mammalian orders } \\
\hline Monotremata & 20 & 3 & 6.8 \\
\hline Marsupialia & 269 & 266 & 1.0 \\
\hline Insectivora & 270 & 345 & 0.8 \\
\hline Dermoptera & 2.2 & 2 & 1.1 \\
\hline Chiroptera & 402 & 951 & 0.4 \\
\hline Primates & 956 & 181 & 5.3 \\
\hline Edentata & 38 & 29 & 1.3 \\
\hline Pholidota & 5 & 7 & 0.7 \\
\hline Lagomorpha & 173 & 58 & 3.0 \\
\hline Rodentia & 1,538 & 1,702 & 0.9 \\
\hline Cetacea & 360 & 76 & 4.8 \\
\hline Carnivora & 1,157 & 231 & 5.0 \\
\hline Tubulidentata & 2.7 & 1 & 2.7 \\
\hline Proboscidea & 94 & 2 & 47 \\
\hline Hyracoidea & 12 & 11 & 1.0 \\
\hline Sirenia & 43 & 4 & 10.8 \\
\hline Perissodactyla & 142 & 16 & 8.9 \\
\hline Artiodactyla & 1,124 & 187 & 6.0 \\
\hline Pinnipedia & 218 & 33 & 6.6 \\
\hline
\end{tabular}


local population of this plant, its restriction to the one volcanic crater would make it very rare by most definitions. Another type of rareness is exhibited by the grass Setaria geniculata, which is found from Massachusetts to California and on down through tropical South America to Argentina and Chile but which is not abundant anywhere. This grass is rare in the sense that its populations are "chronically sparse" (34) everywhere in its broad range.

There have been a variety of proposals for codifying ideas about commonness and rarity. In particular, Rabinowitz et al. (34) have considered three different kinds of questions that arise in thinking about rarity: (i) is the species distributed over a broad geographical area, or is it endemic to some restricted location; (ii) whatever its range, is the species found in a wide variety of habitats, or is it specialized to one kind of site; and (iii) is the species abundant somewhere in its range, or are its numbers everywhere small. These three considerations combine to give eight categories, only one of which (broad distribution, unspecialized habitat, large populations) ordinarily corresponds to the species being called "common." Rabinowitz et al. noted that the archetypal "rare" species, with narrow distribution, specialized habitat, and small numbers, represents only one of several different kinds of rarity. These investigators pursued their ideas by applying them to the plants surveyed in the Biological Flora of the British Isles (which gives detailed distribution maps and notes about the habitat and population of 177 of the 1822 native British plants). Rabinowitz et al. asked 15 colleagues to classify each of the 177 species according to the eightfold category scheme described above (35). This process gave clear consensus for 160 of the 177 species, and the results are summarized in Table 1.

Most species (149 versus 11) are abundant somewhere, and most species ( 137 versus 23 ) have a wide geographical range (Table 1$)$. A narrower majority ( 94 versus 66 ) have restricted habitat specificity.

Of the eight categories, species with wide ranges and large population sizes, but restricted habitat specificities, predominate (71
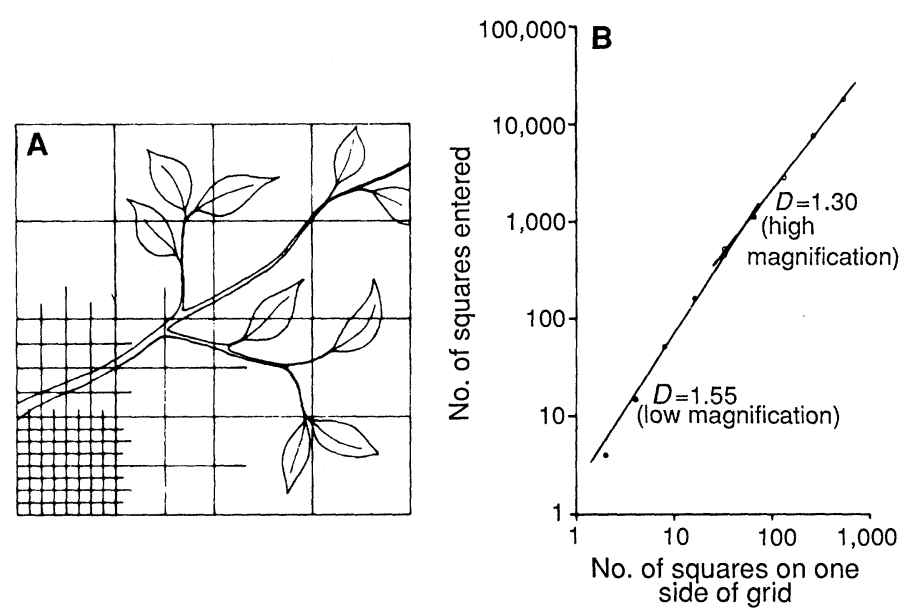

Fig. 3. (A) Photographs of plants at various magnifications were placed under a grid by Morse et al. (21). The number of squares entered by the outline of the plant were counted, starting with a coarse grid of two large squares on one side, then $2^{n}$ squares, with $n$ varying from 2 to 6 or 7 , depending on the grid size. For ease of representation, the plant's leaves in this figure are drawn flat; in reality they are oriented at all angles with respect to the grid. Also for clarity, the progressively finer divisions are only illustrated in one corner of the figure. The logarithm of the number of squares entered by the outline of the plant is then plotted against the logarithm of the number of squares along one side of the grid, as shown in (B). The slope of the line equals the fractal dimension, D. (B) Data gathered in this way for Virginia creeper, photographed without leaves in early spring. The twigs were photographed at one scale, then parts of the same twigs were rephotographed at a higher magnification, permitting $D$ to be estimated at two levels of resolution.
Table 4. Estimated numbers of host-specific canopy beetles on Luehea seemannii, classified into trophic groups (49).

\begin{tabular}{lccc}
\hline $\begin{array}{c}\text { Trophic } \\
\text { group }\end{array}$ & $\begin{array}{c}\text { Number of } \\
\text { species }\end{array}$ & $\begin{array}{c}\text { Estimated } \\
\text { fraction } \\
\text { host-specific } \\
(\%)\end{array}$ & $\begin{array}{c}\text { Estimated } \\
\text { number of } \\
\text { host-specific } \\
\text { species }\end{array}$ \\
\hline Herbivores & 682 & 20 & 140 \\
Predators & 296 & 5 & 15 \\
Fungivores & 69 & 10 & 7 \\
Scavengers & 96 & 5 & 5 \\
$\quad$ Total & $1100+$ & - & 160 \\
\hline
\end{tabular}

of 160 species, or $44 \%$ ). Most of these "rare habitat" species are specialists of marsh, sand dunes, bogs, or forest floors; wherever their habitat exists, they are predictably present (36). The category that is conventionally called "common" comes a close second, exemplified by species such as heather, Calluna vulgaris, or English oak, Quercus robur (58 of 160 species, or $36 \%$ ). The remaining six categories are all less well represented, collectively accounting for only $20 \%$ of the total. The most frequent of these six are what are usually called "endemic rarities," specializing in one type of habitat but abundant in that habitat (14 of 160 species, or 9\%); the Lady Orchid, Orchis purpurea, in Kent is an example. Other categories are uncommon, and one is unrepresented in the British flora: Rabinowitz et al. found no species with small populations in a variety of habitats but with a narrow geographic distribution. The absence of this category may reflect the small sample size, or it may reflect ecological mechanisms that are not yet fully understood.

We need more of these kinds of empirical studies of the multifactorial determinants of commonness and rarity (37). Not only do such studies illuminate fundamental questions about diversity, but they have practical implications for conservation biology. For instance, Table 1 helps justify the attention traditionally given by conservationists to "endemic rarities": not only are these species, with their narrow ranges and restricted habitat specificities, easily destroyed, but they are also numerically the most prevalent category of rare plants. Rabinowitz et al. speculated, moreover, that a better understanding of how endangered and extinct species are apportioned among their eight categories (or among other, alternative categories) may offer "clues about the causes of the endangered state" $(34$, p. 200$)$.

\section{How Many Living Species Have Been Recorded?}

So far, this article has dealt with issues that must be resolved if we are ever to estimate the number of species in a given region, or on Earth, from basic principles. The second part of the article now reviews our current ignorance about the simple facts of how many species there actually are.

Living things may be divided into five kingdoms, distinguished by different levels of cellular organization and modes of nutrition. Two of these kingdoms, the prokaryotic monerans and the eukaryotic protists, comprise microscopic unicellular organisms, and together they account for something like $5 \%$ of recorded living species. The fungal and plant kingdoms represent roughly another $22 \%$ of species. The animal kingdom thus comprises the majority (more than $70 \%$ ) of all recorded living species (38). Table 2 gives a rough account of how the species in the different animal phyla are apportioned according to the habitat of the adult creatures; each phylum represents a distinct body plan, with fundamental differences that distinguish it from all the others (39). 

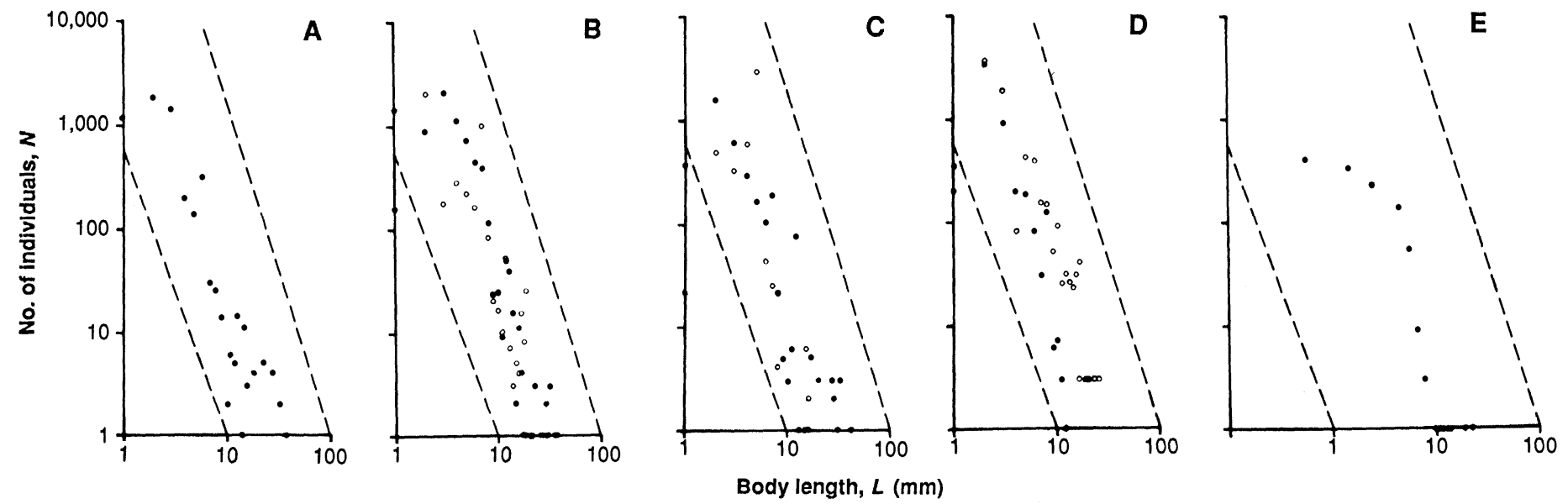

Fig. 4. Data plotted by Morse et al. (21) on the number of individual arthropods (mainly insects) of different body lengths, collected from vegetation: (A) understory foliage in primary forest in Costa Rica; (B) Osa secondary vegetation (solid dots) and Kansas secondary vegetation (open dots); (C) Tabago primary riparian vegetation (solid dots) and Icacos vegetation (open dots); (D) understory foliage in cacao plantations in Dominica (solid dots) and in Costa Rica (open dots); and (E) birch trees at

Table 2 shows that most phyla are found in the sea, and more particularly in benthic environments; many phyla are found only in benthic habitats. On the other hand, by far the most abundant category of recorded living species is terrestrial insects. To a rough approximation and setting aside vertebrate chauvinism, it can be said that essentially all organisms are insects. Hutchinson (40, p. 149) has suggested that "the extraordinary diversity of the terrestrial fauna, which is much greater than that of the marine fauna, is clearly due to the diversity provided by terrestrial plants." Although it is true that in the sea vegetation does not form a structured environment (except close to shore) and that species generally have large geographical ranges (and the oceans are contiguous), closer examination suggests that there are subtle boundaries to dispersal in the sea and that latitudinal zonation is often more marked in the sea than on land (41). Viewing these questions in another light, Ray (42) has observed that although the sea contains only $20 \%$ of all animal species, it contains systematically higher proportions of higher taxonomic units, culminating in $90 \%$ or more of all classes or phyla (largely because all phyla are found in the sea, and the bulk of classes are exclusively marine). These facts make it plain that the factors influencing how many species there are in any one placefood web structure, relative abundance, species-size patterns, and so on-can operate differently in different environments and on different spatial scales.

Any interpretation of information about diversity, such as that summarized in Table 2 , is clouded by uncertainties about how different two groups of organisms have to be before we call them different species, and by the fact that some taxa (for example, vertebrates) have been studied in vastly more detail than others (for example, mites). Even within very well studied groups, some workers recognize many more species than others. This is especially the case for organisms that can reproduce asexually; thus some taxonomists see around 200 species of the parthenogenetic British blackberry, others see only around 20 (and a "lumping" invertebrate taxonomist may concede only 2 or 3 ). Some strongly inbreeding populations are almost as bad, with "splitters" seeing an order of magnitude more species than do "lumpers" (43). At a more fundamental level, Selander (44) observed that different strains of what is currently classified as a single bacterial species, Legionella pneumophila, have nucleotide sequence homologies (as revealed by DNA hybridization) of less than $\mathbf{5 0 \%}$; this is as large as the characteristic

Skipwith Common, North Yorkshire. The lower bound prediction that, for an order of magnitude decrease in body length, there should be a roughly 500 -fold increase in the number of individuals, is indicated by the lower dashed line on each graph. The upper bound prediction-roughly 2000 -fold increase for an order of magnitude decrease in body length-is shown by the upper dashed line.

genetic distance between mammals and fishes. Relatively easy exchange of genetic material among different "species" of microorganisms could mean that basic notions about what constitutes a species are necessarily different for vertebrates than for bacteria. But I think there are likely also to be systematic trends toward greater lumping of species of small and relatively less-studied organisms, and toward greater splitting as we approach the furries and featheries.

In Table 3, I attempt to give a rough impression of how the efforts of professional taxonomists and systematists are currently distributed among the major groups of organisms. Obviously the vertebrates, which comprise only $3 \%$ of all animal species, receive a disproportionate amount of attention. One result is that new birds continue to be found at the rate of about three species per year (against a total of around 8000 species), and new mammals at the rate of around one genus per year (against a total of around 600 genera), which contrasts with the possibility that there may be more than ten insect species for every one yet classified (45).

Setting all these reservations and biases aside, the total number of living organisms that have received Latin binomial names is currently around 1.5 million or so (46). Amazingly, there is as yet no centralized computer index of these recorded species. It says a lot about intellectual fashions, and about our values, that we have a computerized catalog entry, along with many details, for each of several million books in the Library of Congress but no such catalog for the living species we share our world with. Such a catalog, with appropriately coded information about the habitat, geographical distribution, and characteristic abundance of the species in question (no matter how rough or impressionistic), would cost orders of magnitude less money than sequencing the human genome; I do not believe such a project is orders of magnitude less important. Without such a factual catalog, it is hard to unravel the patterns and processes that determine the biotic diversity of our planet.

\section{How Many Living Species Are There?}

Until recently, the total number of species was thought to be around 3 million to 5 million. This estimate was obtained roughly as follows (46). For the species of mammals, birds, and other larger animals that are relatively well enumerated, there are roughly twice 
as many species in tropical regions as in temperate ones. The total number of species actually named and recorded is around 1.5 million, and two-thirds of these are found in temperate regions. Most of these are insects. But most insects that have actually been named and taxonomically classified are from temperate zones. Thus, if the ratio of numbers of tropical to temperate species is the same for insects as for mammals and birds, we may expect there to be something like two yet-unnamed species of tropical insects for every one named temperate species. Hence the overall crude estimate of a total of roughly three times the number currently classified, or around 3 million to 5 million.

This estimate is open to several questions. For one thing, the total includes relatively few species of bacterial, protozoan, and helminth parasites, largely because such parasites are usually studied in connection with economically important animal hosts. But it could be that essentially every animal species is host to at least one specialized such parasitic species (47), which would immediately double the estimated total. For another thing, the Acarina (mites), both tropical and temperate, are even less well studied than tropical insects; it was largely tropical insects that carried the estimate from the known 1.5 million to 3 million to 5 million, and mites could carry it significantly higher.

An indirect approach to the question of the number of species whose body size is small is through studies of species-size relations, such as that in Fig. 2. Figure 6 depicts a very crude estimate of the global totals of terrestrial animal species in different size categories (classified, on a logarithmic scale, according to characteristic body
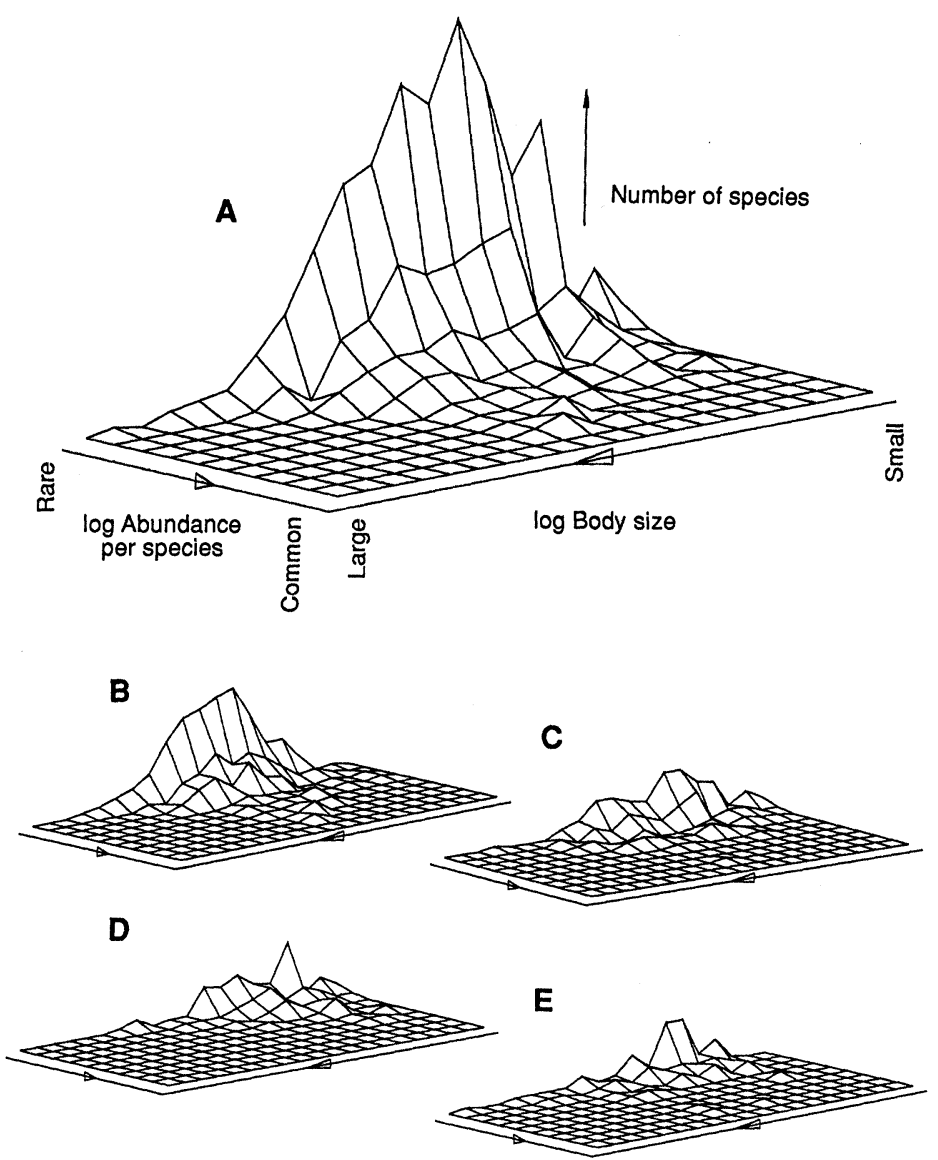

Fig. 5. (A) The height of each intersection is proportional to the number of beetle species that have a particular combination of body length [plotted logarithmically on a scale that extends from $0.5 \mathrm{~mm}$, "small," to $30 \mathrm{~mm}$, "large"] and abundance [plotted as logarithms to the base 2, on the conventional "octave" scale of Preston (15)]; for details, see (29). (B through E) The same information for the separate beetle guilds of herbivores, predators, fungivores, and scavengers, respectively (29). length); the data in Fig. 6 are the result of a multitude of rough and uncertain estimates (18). The dashed line indicates the scaling of numbers of species as $L^{-2}(20)$; the fractal considerations reviewed in connection with Figs. 3 and 4 suggest the scaling might more appropriately be somewhere between $L^{-1.5}$ and $L^{-3}(48)$. Whatever the detailed scaling relation at larger body sizes, it clearly breaks down for organisms whose characteristic body length is significantly below $1 \mathrm{~cm}$. But these are exactly the same creatures-insects, mites, and the like-that have received relatively little attention from taxonomists. Because we lack a fundamental understanding of the size-species relation itself, there is no reason to expect a simple extrapolation of the scaling law for large sizes to estimate accurately the number of unclassified smaller species. It is, however, interesting that the total number of species obtained by extrapolating down to around $1 \mathrm{~mm}$ or so is in the range 10 million to 50 million.

A sounder basis for an upward revision of the estimated number of species comes from Erwin's studies of the insect fauna in the canopy of tropical trees (49). Using an insecticidal fog to "knock down" the canopy insects, Erwin found that most tropical arthropod species appear to live in the tree tops. This is not so surprising, because this is where there is most sunshine as well as most green leaves, fruits, and flowers.

Erwin's original studies (49) were on canopy-dwelling beetles (including weevils) collected from Luehea seemannii trees in Panama over three seasons. He found more than 1100 species of such beetles, distributed among the categories of herbivore, predator, fungivore, and scavenger as shown in Table 4 . To use this information as a basis for estimating the total number of insect species in the tropics, one needs to know what fraction of the fauna are specific to the particular tree species or genus under study; unfortunately, there are essentially no data bearing on this point. Erwin estimated $20 \%$ of the herbivorous beetles to be specific to Luehea (in the sense that they must use this tree species in some way for successful reproduction) (Table 4); the overall answer is more sensitive to this guess than to the corresponding figures of $5 \%, 10 \%$, and $5 \%$ for predator, fungivore, and scavenger beetles, respectively. In this way, one arrives at the estimate of around 160 species of canopy beetles specific to a typical tropical tree.

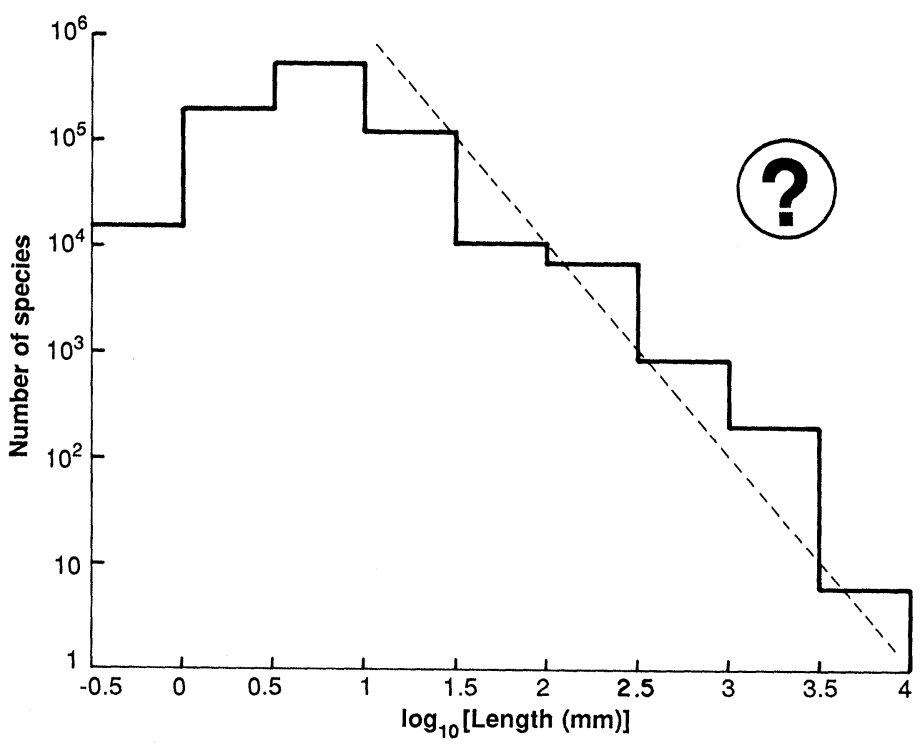

Fig. 6. A crude estimate of the distribution of number of species of all terrestrial animals, categorized according to characteristic length $L$. The dashed line indicates the relation $S \sim L^{-2}$, as in Fig. 2 ( $S$ is number of species) [after (18)]. The question mark emphasizes the crudity of these estimates and the inadequacy of the data for small size classes. 
Several other assumptions are needed to pyramid this estimate of 160 host-specific species of canopy beetles per tree to 30 million species in total. Slightly simplified, the argument runs as follows. First, Erwin noted that beetles represent $40 \%$ of all known arthropod species, leading to an estimate of around 400 canopy arthropod species per tree species. Next, Erwin suggested the canopy fauna is at least twice as rich as the forest-floor fauna and is composed mainly of different species; this increases the estimate to around 600 arthropod species that are specific to each species or genus-group of tropical tree. Finally, using the estimate of 50,000 species of tropical trees (50), Erwin arrived at the possibility that there are $\mathbf{3 0}$ million tropical arthropods in total. This estimate has been widely cited, often without full appreciation of the chain of argument underlying it.

Although it is easy to cavil at each step in Erwin's argument, the work is important in providing a new and focused approach to the problem of estimating how many species there are. Erwin does not so much answer the question as define an agenda of research.

First, the overall estimate depends almost linearly on the necessarily arbitrary assumption that $20 \%$ of the herbivorous beetles are found only on one species or genus-group of tree; changing this number to $10 \%$ would halve the global estimate to 15 million species. I think it likely that insects feeding in the canopies of rainforest trees could be significantly less specialized in their use of food plants than are temperate insects, in order to help them deal with the sparse distribution of many tropical trees. Experiments that "knocked down" the canopy insect fauna from each of many neighboring trees of different species could shed light on these issues and provide a firmer basis for the estimates in the last column of Table 4 (51).

Second, the fact that $40 \%$ of taxonomically classified arthropod species are beetles is of doubtful relevance if, in truth, essentially all arthropods are unclassified tropical canopy dwellers. What we need to know is the fraction of the canopy fauna that are beetles. Again, this information could be obtained by systematic studies of the overall arthropod fauna in the canopies of a variety of tropical trees.

Third, the assumption that there are roughly two canopy species for each forest-floor species is also amenable to systematic study. Such studies should, in my view, reach below the forest floor into the soil, attempting to get a better idea of the species diversity of decomposing animals (including nematodes and other helminths) and other soil-dwellers.

More generally, I believe our ignorance of tropical mites-to name but one group-is at least as great as the ignorance about beetles and other arthropods that Erwin has exposed. These other groups may be similarly diverse. One proposal that is ambitious by ecological standards (although not by those in the physical sciences) is to assemble a team of taxonomists, with a comprehensive range of expertise, and then make a rough list of all the species found in one representative hectare in the tropical rain forest; it would be better to census several such sites (52). Until this is done, I will not trust any estimate of the global total of species.

\section{Coda}

For most of the history of life on Earth that is preserved in the fossil record, rates of extinction and rates of speciation have been roughly commensurate. If, however, we assume that something like half the extant species evolved in the last 50 million to 100 million years and that maybe half of all extant species will become extinct in the next 50 to 100 years if current rates of tropical deforestation continue, then contemporary rates of speciation are of order 1 million times slower than rates of extinction (53). Were speciation rates plotted as the $y$-axis on a graph $10 \mathrm{~cm}$ high, then on the same scale extinction rates would require an $x$-axis extending $100 \mathrm{~km}$.

These circumstances give a special urgency to the kinds of studies called for above. Unlike essentially all other scientific disciplines, conservation biology is a science with a time limit, with the clock ticking faster as the human population continues to increase. We need to understand the world of living things for the same fundamental reasons that we need to understand the physics of the unimaginably small and of the unimaginably large. We also need such understanding to manage the biosphere in a sustainable way (which we do not appear to be doing at present) and to design rational strategies for preserving some habitats while exploiting others in ways that allow some fraction of the original flora and fauna to persist. I believe future generations will find it blankly incomprehensible that we are devoting so little money and effort to the study of these questions.

\section{REFERENCES AND NOTES}

1. The details of 40 of these webs are fully documented in J. E. Cohen, Food Webs and Niche Space (Princeton Univ. Press, Princeton, NJ, 1978) and F. Briand, Ecology 64,253 (1983). The frequency distribution of chain lengths and other properties have been reported for all 113 webs in J. E. Cohen, F. Briand, C. M. Newman, Proc. R. Soc. London Ser. B 228, 317 (1986).

2. F. Briand and J. E. Cohen, Science 238, 956 (1987).

3. Other problems in the compilation of such catalogs of food webs include the following: one wants the "community" web, not a subset of species traced up from one resource or down from one top predator; one must decide, arbitrarily, which links are regarded as too weak or too unusual to list; different researchers may have followed different procedures or had different biases in tabulating individual webs; and so on. For further discussion, see R. M. May, Nature 301, 566 (1983).

4. J. E. Cohen, C. M. Newman, F. E. Briand, Proc. R. Soc. London Ser. B 224, 449 (1985).

5. J. E. Cohen and C. M. Newman, ibid., p. 421. This study is based on 62 food webs only.

6. P. H. Warren and J. H. Lawton, Oecologia (Berlin) 74, 231 (1987).

7. B. A. Hawkins and J. H. Lawton, Nature 326, 788 (1987).

8. J. H. Lawton, personal communication.

9. These patterns depend significantly on the range of the host plant: D. R. Strong, J. H. Lawton, T. R. E. Southwood, Insects on Plants (Blackwell, Oxford, 1984); H. C. Godfray, J. Econ. Entomol. 9, 163 (1984); P. W. Price, Evolutionary Biology of Parasites (Princeton Univ. Press, Princeton, NJ, 1980).

10. M. J. Jeffries and J. H. Lawton, Freshwater Biol. 15, 105 (1985); F. Briand and J. E. Cohen, Nature 307, 264 (1984).

11. This number of direct interactions with 3 to 5 other species is disconcertingly evocative of Miller's observation that people tend to recall $7 \pm 2$ items for lists of very varied lengths [G. A. Miller, Psychoanal. Rev. 63, 81 (1956)].

12. R. T. Paine, J. Anim. Ecol. 49, 667 (1980).

13. F. A. Bazzaz, Ecology 56, 485 (1975).

14. D. Tilman, Resource Competition and Community Structure (Princeton Univ. Press, Princeton, NJ, 1982); R. M. May, Ed., Theoretical Ecology: Principles and Applications (Sinauer, Sunderland, MA, 1981).

15. F. W. Preston, Ecology 43, 185 (1962); R. H. MacArthur and E. O. Wilson, Island Biogeography (Princeton Univ. Press, Princeton, NJ, 1967).

16. R. M. May, in Ecology of Species and Communities, M. Cody and J. M. Diamond, Eds. (Harvard Univ. Press, Cambridge, MA, 1975), pp. 81-120.

17. G. Sugihara, Am. Nat. 116, 770 (1980).

18. R. M. May, in Diversity of Insect Faunas, L. A. Mound and N. Waloff, Eds. (Blackwell, Oxford, 1978), pp. 188-204.

19. L. Van Valen, Evolution 27, 27 (1973). The pattern in Fig. 2 (and in Fig. 6) could be somewhat changed if the large mammals that have become extinct over the last million years or so are included.

20. G. E. Hutchinson and R. H. MacArthur, Am. Nat. 93, 117 (1959).

21. D. R. Morse, J. H. Lawton, M. M. Dodson, M. H. Williamson, Nature 314, 731 (1985).

22. D. Griffiths, Am. Nat. 127, 140 (1986); D. Strayer, Oecologia (Berlin) 69, 513 (1986).

23. J. H. Brown and B. A. Maurer, Am. Nat. 130, 1 (1987).

24. E. D. Odum, Fundamentals of Ecology (Saunders, Philadelphia, 1953)

25. R. H. Peters, The Ecological Implications of Body Size (Cambridge Univ. Press, Cambridge, MA, 1983).

26. B. B. Mandelbrot, Fractals: Form, Chance, and Dimension (Freeman, San Francisco, 1977); C. Loehle, Spec. Sci. Tech. 6, 131 (1983)

27. R. M. May, in Ecological Concepts, J. M. Cherrett, Ed. (Blackwell, Oxford, in press).

28. J. Damuth, Nature 230, 699 (1981); R. H. Peters and J. V. Raelson, Am. Nat. 124, 498 (1984); R. H. Peters and K. Wassenberg, Oecologia (Berlin) 60, 89 (1983); J. H. Brown and B. A. Maurer, Nature 324, 248 (1986).

29. D. R. Morse, N. E. Stork, J. H. Lawton, J. Ecol. Entomol. 13, 25 (1988).

30. I. Hanski, Oikos 38, 210 (1982).

31. J. H. Brown, Am. Nat. 124, 255 (1984).

32. T. Root, Atlas of Wintering North American Birds (Univ. of Chicago Press, Chicago, 
1988).

33. E. H. Rapoport, Areogeography: Geographical Strategies of Species (Pergamon, Oxford, 1982).

34. D. Rabinowitz, S. Cairns, T. Dillon, in Conservation Biology, M. E. Soule, Ed. (Sinauer, Sunderland, MA, 1986), pp. 182-204.

35. The 177 plant species in the British Flora are clearly unlikely to be a random subset of the entire 1822 plant species in Britain. Understandably, very widespread species tend to be overrepresented, at the expense of middling species. Species with highly restricted distributions, however, form about 30\% both of the British Flora and of the entire flora. For further details about possible biases, and about the consensual process among 15 ecologists and systematists, see (34).

36. The category of "rare habitat" may be overrepresented in the British Flora by virtue of the country's long coastline and many maritime species.

37. See, for example, the discussion of sparse and patchily distributed species in speciesrich plant communities by P. J. Grubb [in Community Ecology, J. M. Diamond and T. J. Case, Eds. (Harper and Row, New York, 1986), pp. 207-226] and of experimental design in demographic studies of rare plants by J. Travis and R. Sutter [Natural Areas J. 6, 3 (1987)].

38. V. Pearse, Living Invertebrates (Blackwell, Oxford, 1987).

39. There are, of course, varying opinions about what constitutes a fundamentally different body plan, which is why different schemes recognize from 25 to 35 animal phyla.

40. G. E. Hutchinson, Am. Nat. 93, 145 (1959).

41. These ideas were developed further by E. C. Pielou, Biogeography (Wiley, New York, 1979).

42. G. C. Ray, Am. Zool. 25, 451 (1985).

43. Notable examples are provided by Erophila and Arabidopsis, British plants in the mustard family.

44. R. K. Selander, in Population Genetics and Molecular Evolution, T. Ohta and K. Aoki, Eds. (Springer-Verlag, Berlin, 1985), pp. 85-106.

45. J. M. Diamond, Nature 315, 538 (1985).
46. P. H. Raven, Bull. Entomol. Soc. Am. 29, 5 (1983).

47. C. A. Toft, in Community Ecology, J. M. Diamond and T. J. Case, Eds. (Harper and Row, New York, 1986), pp. 445-463.

48. In an essentially one-dimensional environment with fractal dimension $D$, Hutchinson and MacArthur's (20) argument suggests a scaling of $S \sim L^{-D}$; in an essentially two-dimensional environment, the scaling is $S \sim L^{-2 D}$. When combined with the estimate $D \sim 1.5(21)$, this gives the result in the text.

49. T. L. Erwin and J. C. Scott, Coleopt. Bull. 34, 305 (1980); T. L. Erwin, ibid. 36, 74 (1982); Bull. Entomol. Soc. Am. 29, 14 (1983).

50. R. Howard, personal communication, cited in (43)

51. See, for example, N. E. Stork, Ecol. Entomol. 12, 69 (1987).

52. I suggest 1 ha as the smallest meaningful area for such a study, although not the least of our problems is that we do not understand just what the smallest scale need be to give sensible answers.

53. A. P. Dobson, personal communication.

54. Table 3 was compiled by A. P. Dobson, with help from A. M. Lyles and A. Merenlender. The number of species is taken from R. F. K. Barnes, A Synoptic Classification of Living Organisms (Blackwell, Oxford, 1983); most of the numbers are for recorded species, but some (especially nematodes and insects, as emphasized by the question mark) are Barnes's estimates. The numbers of publications come from The Zoological Record, averaged over the years 1978 through 1987 (with the coefficient of variation of the annual number shown in parentheses). The Zoological Record lists papers covering every aspect of the zoology of animals (scanning over 6000 journals and other documents), except for insects, where only publications dealing with systematics, taxonomy, or nomenclature are given; Table 3 therefore underestimates, by an unknown factor, work on insects relative to that on other animals.

55. This article has been shaped by helpful suggestions from R. K. Colwell, P. J DeVries, W. D. Hamilton, A. P. Dobson, H. S. Horn, M. Kreitman, J. H. Lawton, J. May, C. A. Toft, and two anonymous reviewers. Supported in part by NSF grant DMS87-03503.

\title{
The Ecological Context of Life History Evolution
}

\author{
Linda Partridge and Paul H. Harvey
}

\begin{abstract}
Life histories are the probabilities of survival and the rates of reproduction at each age in the life-span. Reproduction is costly, so that fertility at all ages cannot simultaneously be maximized by natural selection. Allocation of reproductive effort has evolved in response to the demographic impact of different environments but is constrained by genetic variance and evolutionary history.
\end{abstract}

$\mathrm{E}$ VEN THE MOST FAMILIAR ORGANISMS HAVE VERY DIVERSE life histories. Most small birds, such as chickadees or great tits, breed in the spring following their birth, and continue to nest every year until their death. As adults, they have a 50 percent chance of surviving each successive winter. In sharp contrast, most Pacific salmon breed in a suicidal burst as 3-year-olds. Oak trees have high adult survival rates, take more than 3 years before producing even their first few acorns, but then step up production until their acorns are numbered in thousands each year.

Making such diversity intelligible is one reason for studying life history evolution. Another is to predict the ways in which populations will respond to changed environments, including harvesting. Understanding life history diversity means facing fundamental questions about the functioning of organisms: What determines the maximum possible rate of reproduction? What developmental and physiological processes would have to be altered to increase the potential life-span? Why is rapid growth during development often associated with an elevated risk of morality? Answers to these kinds of questions are important in agricultural production and medicine, as well as ecology. Nevertheless, the subject is firmly rooted in ecology because, as we shall see, life histories evolve largely in response to the impact of different environments on the survival and fertility of different age-classes.

Our aim in this article is to evaluate the successes and limitations of the adaptationist approach to understanding life history evolution. It has been claimed that such an approach is doomed (1). In contrast, we shall argue that, when appropriately handled, it can have considerable utility for understanding both the diversity of life histories and the mechanisms constraining their form. We do not provide a comprehensive account, for which reviews are already available (2-4). We first outline the demographic model underlying most adaptationist interpretations of life history variation before going on to show how optimal life histories might be realized. We L. Partridge is a reader in the Department of Zoology, University of Edinburgh, West
Mains Road, Edinburgh EH9 3JT, UK. P. H. Harvey is a lecturer in the Department of Zoology, University of Oxford, South Parks Road, Oxford, OXI 3PS, UK. 
http://www.jstor.org

\title{
LINKED CITATIONS
}

- Page 1 of 3 -

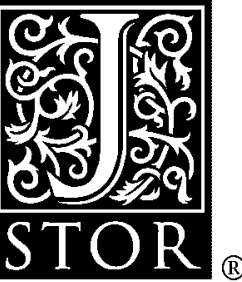

You have printed the following article:

How Many Species are There on Earth?

Robert M. May

Science, New Series, Vol. 241, No. 4872. (Sep. 16, 1988), pp. 1441-1449.

Stable URL:

http://links.jstor.org/sici?sici=0036-8075\%2819880916\%293\%3A241\%3A4872\%3C1441\%3AHMSATO\%3E2.0.CO\%3B2-B

This article references the following linked citations. If you are trying to access articles from an off-campus location, you may be required to first logon via your library web site to access JSTOR. Please visit your library's website or contact a librarian to learn about options for remote access to JSTOR.

\section{References and Notes}

\author{
${ }^{1}$ Environmental Control of Food Web Structure \\ Frederic Briand \\ Ecology, Vol. 64, No. 2. (Apr., 1983), pp. 253-263. \\ Stable URL: \\ http://links.jstor.org/sici?sici=0012-9658\%28198304\%2964\%3A2\%3C253\%3AECOFWS\%3E2.0.CO\%3B2-0 \\ ${ }^{2}$ Environmental Correlates of Food Chain Length \\ Frédéric Briand; Joel E. Cohen \\ Science, New Series, Vol. 238, No. 4829. (Nov. 13, 1987), pp. 956-960. \\ Stable URL: \\ http://links.jstor.org/sici?sici=0036-8075\%2819871113\%293\%3A238\%3A4829\%3C956\%3AECOFCL\%3E2.0.CO\%3B2-T

\footnotetext{
${ }^{12}$ Food Webs: Linkage, Interaction Strength and Community Infrastructure R. T. Paine

The Journal of Animal Ecology, Vol. 49, No. 3. (Oct., 1980), pp. 666-685.

Stable URL:

http://links.jstor.org/sici?sici=0021-8790\%28198010\%2949\%3A3\%3C666\%3AFWLISA\%3E2.0.CO\%3B2-1

${ }^{13}$ Plant Species Diversity in Old-Field Successional Ecosystems in Southern Illinois

F. A. Bazzaz

Ecology, Vol. 56, No. 2. (Early Spring, 1975), pp. 485-488.

Stable URL:

http://links.jstor.org/sici?sici=0012-9658\%28197521\%2956\%3A2\%3C485\%3APSDIOS\%3E2.0.CO\%3B2-F
}

NOTE: The reference numbering from the original has been maintained in this citation list. 
http://www.jstor.org

\title{
LINKED CITATIONS
}

- Page 2 of 3 -

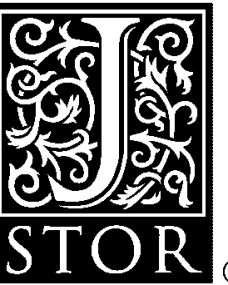

\footnotetext{
${ }^{15}$ The Canonical Distribution of Commonness and Rarity: Part I

F. W. Preston

Ecology, Vol. 43, No. 2. (Apr., 1962), pp. 185-215.

Stable URL:

http://links.jstor.org/sici?sici=0012-9658\%28196204\%2943\%3A2\%3C185\%3ATCDOCA\%3E2.0.CO\%3B2-8
}

${ }^{17}$ Minimal Community Structure: An Explanation of Species Abundance Patterns George Sugihara

The American Naturalist, Vol. 116, No. 6. (Dec., 1980), pp. 770-787.

Stable URL:

http://links.jstor.org/sici?sici=0003-0147\%28198012\%29116\%3A6\%3C770\%3AMCSAEO\%3E2.0.CO\%3B2-9

\section{${ }^{19}$ Body Size and Numbers of Plants and Animals}

Leigh Van Valen

Evolution, Vol. 27, No. 1. (Mar., 1973), pp. 27-35.

Stable URL:

http://links.jstor.org/sici?sici=0014-3820\%28197303\%2927\%3A1\%3C27\%3ABSANOP\%3E2.0.CO\%3B2-A

\author{
${ }^{20}$ A Theoretical Ecological Model of Size Distributions Among Species of Animals \\ G. E. Hutchinson; Robert H. MacArthur \\ The American Naturalist, Vol. 93, No. 869. (Mar. - Apr., 1959), pp. 117-125. \\ Stable URL: \\ http://links.jstor.org/sici?sici=0003-0147\%28195903\%2F04\%2993\%3A869\%3C117\%3AATEMOS\%3E2.0.CO\%3B2-X
}

\section{${ }^{22}$ Size-Abundance Relations in Communities}

David Griffiths

The American Naturalist, Vol. 127, No. 2. (Feb., 1986), pp. 140-166.

Stable URL:

http://links.jstor.org/sici?sici=0003-0147\%28198602\%29127\%3A2\%3C140\%3ASRIC\%3E2.0.CO\%3B2-N

\footnotetext{
${ }^{23}$ Evolution of Species Assemblages: Effects of Energetic Constraints and Species Dynamics on the Diversification of the North American Avifauna

James H. Brown; Brian A. Maurer

The American Naturalist, Vol. 130, No. 1. (Jul., 1987), pp. 1-17.

Stable URL:

http://links.jstor.org/sici?sici=0003-0147\%28198707\%29130\%3A1\%3C1\%3AEOSAEO\%3E2.0.CO\%3B2-4
}

NOTE: The reference numbering from the original has been maintained in this citation list. 
http://www.jstor.org

\title{
LINKED CITATIONS \\ - Page 3 of 3 -
}

\author{
${ }^{28}$ Relations between Individual Size and Mammalian Population Density \\ Robert Henry Peters; John Verner Raelson \\ The American Naturalist, Vol. 124, No. 4. (Oct., 1984), pp. 498-517. \\ Stable URL: \\ http://links.jstor.org/sici?sici=0003-0147\%28198410\%29124\%3A4\%3C498\%3ARBISAM\%3E2.0.CO\%3B2-Z
}

\author{
${ }^{31}$ On the Relationship between Abundance and Distribution of Species \\ James H. Brown \\ The American Naturalist, Vol. 124, No. 2. (Aug., 1984), pp. 255-279. \\ Stable URL: \\ http://links.jstor.org/sici?sici=0003-0147\%28198408\%29124\%3A2\%3C255\%3AOTRBAA\%3E2.0.CO\%3B2-2
}

${ }^{40}$ Homage to Santa Rosalia or Why Are There So Many Kinds of Animals?

G. E. Hutchinson

The American Naturalist, Vol. 93, No. 870. (May - Jun., 1959), pp. 145-159.

Stable URL:

http://links.jstor.org/sici?sici=0003-0147\%28195905\%2F06\%2993\%3A870\%3C145\%3AHTSROW\%3E2.0.CO\%3B2-D

\author{
${ }^{48}$ A Theoretical Ecological Model of Size Distributions Among Species of Animals \\ G. E. Hutchinson; Robert H. MacArthur \\ The American Naturalist, Vol. 93, No. 869. (Mar. - Apr., 1959), pp. 117-125. \\ Stable URL: \\ http://links.jstor.org/sici?sici=0003-0147\%28195903\%2F04\%2993\%3A869\%3C117\%3AATEMOS\%3E2.0.CO\%3B2-X
}

NOTE: The reference numbering from the original has been maintained in this citation list. 